\title{
Interactive comment on "Fluid-mediated,
} brittle-ductile deformation at seismogenic depth: Part I - Fluid record and deformation history of fault-veins in a nuclear waste repository (Olkiluoto Island, Finland)" by Barbara Marchesini et al.

Barbara Marchesini et al.

barbara.marchesini2@unibo.it

Received and published: 21 February 2019

Response to Olivier Vanderhaeghe comments (Referee \#1 - se-2019-5-RC1)

We have much appreciated the constructive review by the first reviewer, Prof. Olivier Vanderhaeghe, who thinks that the paper is clear, well documented and scientifically sound. All his comments and inputs are being taken into account for an improved revised version of the initial submission. There are a few points raised by the reviewer 
version, should our manuscript be accepted for final publication. We report below the reviewer's comments followed by our thoughts and comments.

\section{1) Microstructural analysis}

Reviewer: “... In the microstructural description of quartz veins, the authors refer to "new quartz grains" (illustrated in figure 6d?). After reading the text, it is not clear to me if the authors attribute these "new quartz grains" to quartz that have precipitated from a fluid that has circulated into a fracture or to neoblasts formed by solid-state recrystallization? From the pictures, I would favour solid-state recrystallization but I have the impression that the authors rather imply precipitation in a fracture. Clarify."

Authors: We interpret the new grains as resulting from quartz deformation in the lowtemperature plasticity regime. In such regime, dynamic recrystallisation (typically by bulging and subgrain rotation) and 'neocrystallisation' by nucleation and growth in fractured fragments coexist and compete in the overall microstructural evolution of quartz. Accordingly, the microstructures presented in our paper show evidence for both processes being active during deformation of Qtz I grains. Initial nucleation from circulating fluids along now sealed cracks is proposed to have caused fracture healing and sealing. At the same time, and in light of targeted EBSD analysis that we have performed to better understand Qtz I crystallization in the fault core (see below), we can also document the local importance of dynamic recrystallisation by bulging and subgrain rotation. The combination of both mechanisms recalls the results by Kjøll et al. (2015), which proposed the combination of these mechanisms after a detailed microstructural analysis in quartz veins associated with a thrust, formed at the brittle-ductile transition. To properly address this important aspect, which, as the reviewer's comments indicate is not too clearly addressed in the submitted version of the manuscript, we have decided to introduce in the final version of the paper a specific discussion of this topic supported by a new figure with newly acquired EBSD maps documenting recovery and dynamic recrystallization. 
In this section, the reviewer also asked to provide an example of the cathodoluminescence imaging of Qtz I from the fault core (line 315).

Authors: In the final version of the paper we will exchange panel e) of Figure 6 with the required image.

2) Fluid inclusions analysis

Reviewer: ". . .the composition of the fluid is not specified, except for its salinity in $\mathrm{NaCl}$ equivalent? Are they $\mathrm{CO} 2$ and/or $\mathrm{H} 2 \mathrm{O}$ fluid inclusions? Moreover, in which state are they? Liquid or vapor? Please provide these informations."

Authors: This comment suggests that fluid composition should be reported more clearly in the manuscript, and we will certainly address this and modify the final version accordingly. In section 3 (Applied methods) we show that we systematically cooled the $\mathrm{FI}$ samples to about $-180{ }^{\circ} \mathrm{C}$ and then slowly heated them to detect the potential formation of a solid carbonic phase, eutectic phases, salt hydrates, ice, and clathrates. On a later stage, we heated the samples from room temperature to record Thtot and reported the mode of homogenization (i.e., by bubble or liquid disappearance). The systematic application of this procedure and the determination of only Tmice and Thtot in the studied FIAs (i.e., the failure to detect carbonic phase or salt hydrates), provide microthermometric evidence that the entrapped fluid is aqueous in composition and that it was homogeneous at the time of entrapment. In order to detect low concentrations of $\mathrm{CO} 2$ or other molecular species, we integrated the microthermometric study with Raman spectroscopy analyses. As reported in the manuscript, Raman spectra of the vapour bubbles show invariably a very weak $\mathrm{CH} 4$ signal in addition to the expected, and dominant, $\mathrm{H} 2 \mathrm{O}$ spectrum. Additionally, of the 46 analysed fluid inclusions, only 3 showed a very weak $\mathrm{CO} 2$ signal. Those signals are not from inclusions related to specific quartz microstructures (i.e. intracrystalline healed cracks, WEB's planes, intercrystalline fractures) or specific locations in the fault architecture, so we did not consider them as indicative of any specific process within the fault. This is consistent

Printer-friendly version

Discussion paper 
with petrographic analysis and microthermometric measurements. In light of all these evidences, we think that $\mathrm{CO} 2$ is not an important molecular species of the fault fluid, and this is why we did not consider it explicitly in our model. All this notwithstanding, we dedicated a short paragraph to the performed Raman analyses to prove that we have fully characterized the composition of the synkinematic fluid.

Reviewer: "I am also surprised that only secondary trails and pseudosecondary trails have been identified. Please confirm that there are no primary fluid inclusions forming clusters in the core of quartz grains. It might also be useful distinguish intracrystalline fluid inclusions trails from fluid inclusion trails crosscutting quartz grains."

Authors: As we have documented, the studied quartz crystals are characterized by a complex network of healed cracks and, indeed, also by many fluid inclusions arranged as trails, cross-cutting and superimposed on each other and apparently arranged in clusters. Hence, we could not comfortably identify any primary fluid inclusions. We only identified a few clusters of primary fluid inclusions in the Qtz II vein samples (line 382), but they showed irregular and decrepitated morphologies (they were empty). Thus, microthermometric determinations were not possible in those inclusions and we decided to not emphasize their presence.

Reviewer: "...the use of the term transposition referring to fluid inclusion trails (line 362) is confusing. What is the meaning of the term "transposition" in this context? In structural geology, as far as I know, transposition corresponds to reorientation of a former structure during deformation. I don't think that it applies to the present case according to what is illustrated in figure 9c. I imagine that what is meant is "remobilization" or "redistribution" of the fluids contained in these trails as a consequence of recrystallization. Clarify."

Authors: With the term "transposed" we aimed to document a reorientation and reworking of fluid inclusions as transgranular trails (Figure $9 \mathrm{a}$ and $\mathrm{c}$ ). As documented in Anderson et al. (1990) and Van den Kerkhof et al. (2014), during transposition, 
inclusion arrays are usually re-aligned along a new plane, at a different orientation with respect the original one. We agree with the reviewer about the implied remobilization of the fluid as a consequence of this process. These transposed trails are at high angle to transgranular trails, which we identified as healed fractures. These transposed trails seem to be unrelated to grain boundaries and fluid remobilization along them, as documented in Siebenaller et al. (2016), their Figure 7c and 8d. Transposition is generally associated with complex and multi-stage deformation. Indeed, we used this term and this petrographic documentation to describe and constrain the multiple stages of Qtz I deformation inside the fault core and to indicate the reorientation of inclusion arrays as consequence of recrystallization and to specify that it is associated with a healed crack. To better clarify this aspect and to avoid confusion between the different nomenclatures, we will replace the term "transposed" with the term "remobilization (i.e., "transposition" sensu Anderson et al., 1990)".

Review: "The homogenization temperatures and salinities obtained on the analysis of what is presented as a consistent assemblage of fluid inclusions display rather wide ranges of values. The authors explain this diversity by post-entrapment modification of the fluid inclusions and argue paradoxically that these fluid inclusions with variable characteristics correspond to a homogeneous fluid. As an alternative, I would suggest to consider that these fluid inclusions do not belong to the same "population" or "type" and search for criteria to subdivide the studied assemblages in subsets. The identification of the proportion of $\mathrm{CO} 2$ and $\mathrm{H} 2 \mathrm{O}$ might provide insights to refine the analysis of fluid types."

Authors: We partially replied to this suggestion in the previous comment on fluid composition; however, we extend that discussion here to reply more extensively. The reviewer finds that fluid inclusions belonging to individual assemblages and displaying variable microthermometric properties are a paradox, and suggests finding possible alternative/diverse criteria to subdivide our Fl dataset. This would be, however, in contrast to the well-established definition of "Fluid Inclusion Assemblage", and for this 
reason we exclude the possibility suggested by the reviewer. By definition, a FIA is a petrographically discriminated, cogenetic group of fluid inclusions located along trails, clusters or growth planes of minerals (Bodnar, 2003a; Goldstein, 2003), and represents a single event of fluid entrapment occurring at a specific stage of mineral formation. The properties of a FIA cannot be divided into subsets because they uniquely identify the properties of one fluid found within a microfracture, within a growth plane of a crystal, etc. A single FIA can be trapped either homogeneously or heterogeneously, and the microthermometric properties identifying these types of entrapment are characteristic and distinct (ranges of Tmice, Thtot, homogenization by bubble or liquid disappearance, etc.). Subdividing these properties into subsets would be in contrast with the standard definition of assemblage. In our FIAs we documented extremely variable salinity and final homogenization temperature (Fig. 10), and found that homogenization occurs systematically by bubble disappearance. In the literature, these variabilities are interpreted as products of post-entrapment modifications triggered by host mineral deformation, and we interpreted our data accordingly. Therefore, our statistical approach is in line with the current knowledge and we believe that our proposed reconstruction of the variability of the synkinematic fluid pressure is reasonable. In the revised version of the manuscript, however, we are prepared to discuss the possible presence of more than one fluid generation, specifically in section 5.2 line 518-519, although we prefer to maintain the interpretation of the homogeneous composition of the fluid at the time of trapping.

\section{3) Deformation and fluid circulation model}

Review: "The authors propose a model of repeated brittle-ductile deformation cycle triggered by successive fluid overpressure and evacuation, which is in essence similar to the fault valve model published in several papers by Sibson or Cox, with the nuance that the authors advocate that the studied shear zone is representative of "the" brittle/ductile transition at the time of deformation. It is not clear to me how this is demonstrated by the data, especially with regard to a subvertical strike-slip shear

Interactive

comment
Printer-friendly version

Discussion paper 
zone. Ideally, it should be demonstrated that at higher structural level, brittle deformation dominates and that at lower structural level, ductile deformation dominates. Is this the case?"

Authors: One of the main conclusions of our study is that we document brittle deformation in a specific volume of rock under general ductile conditions. The brittle structures documented in the Qtz I vein from the fault core are characterized by ductile overprinting and this is the evidence that despite the fluid-induced embrittlement, the system was still at the brittle-ductile transition. Consequently, our model, albeit similar in many ways to the fault valve model of Sibson, is different as we show that valve-type process may lead to embrittlement at the brittle-ductile transition, i.e. essentially at one depth level. Moreover, we also want to emphasize that the faults in the Olkiluoto area show the coexistence between brittle and ductile deformation and their cyclical reactivation is documented for several fault systems in the studied area (Aaltonent et al., 2016), documented during the detailed site investigations that have been carried out in the site since the 80's, culminating in the construction of underground galleries in 2004. In particular, most of the fault systems that are characterized by semi-brittle behaviour appear to exploit and reactivate ductile precursors, i.e. mylonites, which formed under amphibolite facies conditions. The reactivation of mylonitic precursors started during the onset of brittle deformation which occurred under retrograde metamorphic conditions. The conjugate fault associated with the strike-slip fault presented in this manuscript shows clear sign of reactivation along the ductile precursor. Moreover, the cyclicity between brittle and ductile deformation documented in the proposed manuscript is the consequence of the fluid overpressure discharge in an overall ductile environment. Only the absence of widespread viscous strain of Qtz II can be interpreted as indicative of some initial exhumation. In light of this, we interpreted that our strike-slip fault system is formed and reactivated basically at the brittle- ductile transition (BDT), but noting also that brittle reactivation of the faults continued as they were further exhumed. But that said, to better clarify this aspect, the addition of the EBSD maps mentioned above can be used to discuss also this aspect of the paper and to pro- 
vide more evidence of dynamic recrystallization and recovery processes during ductile deformation.

Reviewer: "Moreover, the authors propose that the shear zone records deformation during progressive exhumation and cooling, which, as far as I understand, is not consistent with the increase in $\mathrm{P}$ and $\mathrm{T}$ recorded from $\mathrm{t} 1$ to $\mathrm{t} 2$ (and even $\mathrm{t} 3$ when considering the temperature). In order to clarify these points, it is required to discuss the significance of the measures pressure and temperature. Does the pressure correspond to the fluid pressure required for embrittlement, i.e. the yield strength of the host rock or does it correspond to the lithostatic or even hydrostatic pressure? Are the measured temperatures representative of the host rock temperature or do they solely reflect the fluid temperature? In the latter case, is it possible to document if the fluid temperature is higher or lower than the temperature of the host rocks? A related question is where the fluid does come from and where does it go?"

Authors: Actually, the model we propose suggests cyclicity to occur basically at the same depth and not during too significant of an exhumation path "en-route" to the surface. We emphasize that in our case we estimated the Ptrap of the FIAs by combining isochores of FIAs with the T estimated from two mineral-pair geothermometers (chlorite-quartz and stannite-sphalerite), which is a fortunate case for a geological study. The isochores of Fig. 12 highlight the PT loci of the Qtz I and Qtz II fluid isochores, and the $T$ ranges of the mineral geothermometers (vertical dotted lines). Because the mineral-pair temperatures are equilibrium temperatures at which fluid and minerals coexisted within the fault, we consider those values independent constraints, i.e. Ttrap of the FIAs. The pressures we derive from the intersection with the isochores are the vapour pressures of the fluid in the fault, which is independent from the depth of entrapment. We thus consider the Pf estimates to be representative of the pressure of the fluid interacting with (and leading to the embrittlement of) the host-rock. The values are, however, minimum estimates because they are not obtained from primary fluid inclusions. Concerning the thermometric estimations obtained from synkinematic

Interactive comment
Printer-friendly version

Discussion paper 
and authigenic minerals (chlorite and stannite-sphalerite), they represent the temperature of the fluid flowed and then crystallized within the opened fractures. Temperature of the fluid phase is lower $\left(200-350^{\circ} \mathrm{C}\right)$ than the T estimated for the amphibolite facies deformation recorded in the migmatitic host rock. We also performed Raman analysis on the graphite crystals interlayered with chlorite and muscovite along the main fabric of the host rock. We will present this dataset in the second part of the paper (Part II, Prando et al., in prep.).

Review: ". . .the authors consider that the studied shear zone is narrowing implying that the damage zone is representative of an early stage of brittle deformation, which is followed by ductile/brittle deformation localized in the core of the shear zone. This assumption strongly controls the interpretation of the data and the elaboration of the fluid circulation/deformation model. As an alternative, one could consider that the fault zone is widening rather than narrowing. In this case, the damage zone represents a more recent expression of the fault zone than the core zone that has experienced a longer history of deformation. Note that this proposition is in line with the lower temperature and pressure recorded by the fluid inclusions in the damage zone compared to the core zone of the fault, suggesting progressive exhumation of the shear zone during deformation. Please consider this alternative and provide evidences to discard (or favor?) it."

Authors: As to the possibility that the studied deformation zone widened instead of thinning during progressive deformation, we discard this because what we defined Damage Zone contains Qtz I, which we assign beyond any doubt to the initial deformation history of the fault zone. Quartz II, which is found exclusively within the fault core, has been shown to be the expression of a younger, later reactivation. Lack of Qtz II in the Damage Zone points to a narrowing deformation zone with time, irrespective of the TPX conditions of the fluids precipitating the quartz. Considering these aspects, we proposed BFZ300 as an example of Type II shear zone (Fossen, 2016).

The reviewer also asked to implement the bibliography, suggesting valuable papers. 
We accept his suggestions and we will use them to improve the manuscript.

4) Reviewer comments on the annotated section:

Abstract: "This abstract is well-written but could probably shortened by $10 \%$."

Authors: We will shorten the text as much as possible in the revised version of the manuscript.

Interactive

comment

Line 132: "Only strike-slip shear zones are described. Are there any detachment that might have accommodated exhumation?"

Authors: As far as we know, there are no detachments documented in the studied area. But according to Aaltonen et al. (2016), the site is intersected by low-angle fault zones, which also cross-cut the subvertical strike-slip zones, but they are younger in age. Line 347: "intracrystalline deformation" or "dynamic recrystallization"?

Authors: intracrystalline deformation

Line 449: "Specify what you mean by "progressive". Do you call for a strain gradient in space and/or for protracted deformation in time? "

Authors: with the term "progressive" we indicated a progressive strain localization during the fault activity.

Line 450: "How is the ductile-brittle transition zone defined in a strike-slip shear zone? It would be nice to be able to document dominant ductile deformation at lower structural level and dominant brittle deformation at upper structural level."

Authors: We have addressed this issue in replies to comments given earlier. In order to emphasize our case, we repeat here partly the answer given above: our study documents more-or-less coeval ductile-brittle deformation at the ductile-brittle transition, the embrittlement caused by increased fluid pressures and stress drop due to slip. The fault zone was only later reactivated and deformed at higher structural levels during exhumation as documented by Aaltonen et al. (2016) but giving an extended discussion 
on this was not in the scope of our study. Line 458: "10e-h?"

Authors: We wrongly cited the Figure. Yes, this sentence is referred to Figure 10e-h

Line 511: "What do these temperatures represent? Are these representative of the host rock temperature or do they solely reflect the fluid temperature? In any case, how do you explain this increase in P and T with time?"

Interactive

comment

Authors: We partly replied to this comment in the previous section. The estimated temperatures are related to fluid temperatures. Moreover, the variability of the temperature could be due to the heterogeneity of the plutonic bodies at different rates of cooling. Regarding the variability in the fluid pressure, we argue that it could be due to different processes of healing and sealing during the different hydrofracturing events registered by the studied fault zone.

Line 522:" Recall evidences."

Authors: Brittle structures in Qtz I from the fault core are overprinted by dynamic recrystallization.

Line 573:" Where does the fluid comes from and where does it go?"

Authors: We are unfortunately unable to answer because our dataset does not provide appropriate constraints. We can only speculate on these issues, and maybe add some lines in the new version of the manuscript. Current knowledge derived from studies of middle-crust fault zones (especially studies of vein-hosted ore deposits) shows that a variety of sources could contribute to the total budget of vein fluids. In the case of Olkiluoto, $\mathrm{H} 2 \mathrm{O}$ and solutes may be theoretically provided by metamorphic dehydration of rocks located at depth, by transfer of mass from local host rocks, by magmatichydrothermal activity, and even by the mantle. We cannot evaluate the role of all the individual sources, but based on our FI Raman data (i.e., consistent presence of $\mathrm{CH} 4$ in the vapour phase of FIAs) we can speculate that the local paragneiss could have provided solutes and molecular species to the fluid. However, this claim should be 
tested against an appropriate geochemical dataset, which we do not present here. Following the precipitation of quartz, chlorite, sulphides and other minor phases in the fault section we studied, the Olkiluoto fluid flowed towards shallower sections of the crust, possibly interacting with the host rocks found there. This interaction depended for sure on a variety of factors (fluid and rock compositions, fracture geometry and topology, armouring of fracture walls, etc.) that we cannot evaluate with our study.

Interactive

comment

Line 581: "This proposition of exhumation and cooling is not consistent with the increase in $\mathrm{P}$ and $\mathrm{T}$ recorded from $\mathrm{t} 1$ to $\mathrm{t} 2$ (and even $\mathrm{t} 3$ when considering the temperature). Clarify."

Authors: We proposed variable PT conditions during the deformation zone evolution because Qtz II (i.e. the second big reactivation of the fault zone) does not show evidence of crystal-plastic deformation, as documented instead by Qtz I vein from within the fault core. The increase in $\mathrm{Pf}$ and $\mathrm{T}$ are commented in the previous sections.

Interactive comment on Solid Earth Discuss., https://doi.org/10.5194/se-2019-5, 2019. 